\title{
PENERAPAN METODE MONTE CARLO PADA PERENCANAAN JUMLAH PRODUKSI PESTISIDA (Studi Kasus: PT. Petrokimia Kayaku Plant Cair 1)
}

\author{
Dian Safitri ${ }^{(1)}$, Said Salim Dahdah ${ }^{(2)}$, Deny Andesta ${ }^{(3)}$ \\ Program Studi Teknik Industri Universitas Muhammadiyah Gresik \\ Email : Diansafitri018@gmail.com
}

\begin{abstract}
ABSTRAK
Sebuah perusahaan yang terus berkembang harus mampu melakukan perencanaan produksi secara efektif dan efisien dalam memenuhi kebutuhan konsumen agar dapat meminimalisir kondisi overstock dan understock yang dapat merugikan perusahaan. Hal inilah yang menjadi dasar dilakukannya penelitian di PT. Petrokimia Kayaku, yang merupakan perusahaan penghasil produk pestisida di Gresik. Dalam menentukan jumlah produksi yang akan datang digunakan metode Monte Carlo dengan dua model alternatif persediaan yaitu EPQ dan Permintaan Musiman. Data yang digunakan adalah data produksi dan data permintaan harian selama 35 bulan, dengan 5 produk permintaan terbanyak. Kemudian dilakukan pengolahan data menggunakan simulasi dengan metode Monte Carlodengan 5kali replikasi dan perencanaan selama 6 bulan atau 181 hari. Dari simulasi yang telah dilakukan, didapatkan hasil bahwa biaya simpan yang rendah dan servicer level tinggi menggunakan model EPQ. Untuk produk Ceba 125 Ec50 ml dengan Q optimal 11.338 box, biaya simpan Rp. 994.372.513, service level 84,82\%. Produk Petrogud 200 Ec $500 \mathrm{ml}$ dengan Q optimal1.669 box, biaya simpan Rp. 30.794.516, service level 95,84\%. Produk Tombak 189 Ec 400 ml dengan Q optimal1.380 box, biaya simpan Rp. 127.668.961, service level 26,55\%. Produk Kanon 400 Ec Btl Pet 400 mlQ optimal603 box, biaya simpan Rp. 11.520.342, service level 87,95\%. Produk Kanon 400 Ec Btl Pet 100 ml dengan Q optimal 611 box, biaya simpan Rp. 11.687.585, service level 98,70\%.
\end{abstract}

Kata kunci: Perencanaan Produksi, Monte Carlo, Model EPQ, Model Permintaan Musiman, Biaya Simpan, Service Level.

\section{PENDAHULUAN}

Sektor pertanian merupakan sumber yang sangat penting dalam pertumbuhan pasar dalam Negeri bagi sektor non-pertanian seperti sektor industri. Sebagian besar sektor pertanian di Indonesia menggunakan pestisida untuk memberantas hama karena peran pestisida yang cukup besar dalam upaya penyelamatan produksi pertanian dari gangguan hama dan penyakit tanaman (Kementrian Pertanian, 2011).

PT. Petrokimia Kayaku merupakan salah satu anak perusahaan PT. Petrokimia Gresik yang bergerak di sektor agrokimia yang menghasilkan produk utama berupa pestisida, pupuk hayati, probiotik ternak dan sejumlah produk lainnya. Produk-produk PT. Petrokimia Kayaku telah diakui sesuai dengan Standar Internasional FAO - specified for plant protection products, sehingga memenuhi standar keamanan bagi pertanian. PT. Petrokimia Kayaku juga berkomitmen untuk senantiasa mendukung perkembangan sektor pertanian dan perkebunan di Indonesia mewujudkannya dengan pemanfaatan teknologi modern dalam proses produksinya, sehingga menghasilkan produk yang berkualitas dan ramah lingkungan.
Saat ini perusahaan dalam merencanakan jumlah produksinyahanya berdasarkan data penjualan di masa lalu tanpa menggunakan metode khusus yang dapat mengidentifikasi ketidakpastian fluktuasi permintaan, sehingga masih sering terjadi overstock dan understock yang berlebihan dari batas toleransi perusahaan. Untuk overstock batas toleransi maksimalsebesar 5\% dan untuk understock batas toleransi maksimal sebesar $10 \%$.

Dibawah ini adalah data kondisi overstock dan understock yang terjadi pada 3 bulan pertama di tahun 2018.

Tabel 1.1 Data Kondisi Overstock Dan UnderstockTahun 2018(Liter)

\begin{tabular}{|c|r|r|r|r|r|r|}
\hline \multirow{2}{*}{ Nama Produk } & \multicolumn{3}{|c|}{ Understock } & \multicolumn{3}{c|}{ Overstock } \\
\cline { 2 - 7 } & \multicolumn{1}{|c|}{ Jan } & \multicolumn{1}{|c|}{ Feb } & \multicolumn{1}{c|}{ Mar } & \multicolumn{1}{c|}{ Jan } & \multicolumn{1}{c|}{ Feb } & Mar \\
\hline Ceba $125 \mathrm{Ec}-50 \mathrm{ml}$ & -400 & -3.800 & 0 & 0 & 0 & 0 \\
\hline Petrogud $200 \mathrm{Ec} 500 \mathrm{ml}$ & 0 & -4.300 & 0 & 0 & 0 & 0 \\
\hline Tombak $189 \mathrm{Ec} 400 \mathrm{ml}$ & 0 & 0 & 0 & 0 & 3.200 & 4.400 \\
\hline $\begin{array}{c}\text { Kanon } 400 \mathrm{Ec} \mathrm{Btl} \mathrm{Pet} \\
400 \mathrm{ml}\end{array}$ & -56 & 0 & 0 & 0 & 2.400 & 0 \\
\hline $\begin{array}{c}\text { Kanon } 400 \mathrm{Ec} \mathrm{Btl} \mathrm{Pet} \\
100 \mathrm{ml}\end{array}$ & -4.000 & 0 & 0 & 0 & 0 & 0 \\
\hline
\end{tabular}

Untuk menentukan jumlah produksi yang optimal agar dapat mengimbangi ketidakpastian fluktuasi permintaan dan meminimalkan biaya persediaan, namun tidak mengurangi service levelnya yaitu dengan pendekatan simulasi menggunakan metode Monte Carlo dengan membandingkan dua 
alternatif model persediaan yaitu model EPQ dan model permintaan musiman. Model simulasi Monte Carlo adalah suatu metode untuk mengevaluasi secara berulang model probabilistik menggunakan himpunan bilangan acak (random) sebagai masukan. Proses randomisasi ini melibatkan suatu distribusi probabilitas dari variabel-variabel data yang dikumpulkan berdasarkan data masa lalu. Percobaan berulang kali dari data yang telah ada akan menghasilkan suatu pola yang diharapkan dapat digunakan untuk mengelola persediaan.

Dengan proses simulasi yang dilakukan terhadap alternatif yang diusulkan nantinya dapat dipilih hasil simulasi yang menunjukkan selisih adanya jarak yang terkecil antara data persediaan dan permintaan yang dimunculkan dari hasil distribusi probabilitas bilangan acak. Selisih jumlah jarak yang terkecil antara data persediaan dan permintaan mengakibatkan biaya yang dikeluarkan akibat persediaan serta hilangnya kesempatan memenuhi permintaan dapat diminimalkan.

\section{METODOLOGI}

Pada penelitian ini menggunakan metode penelitian deskriptif. Dengan objek penelitian pestisida pada plan wp, dan dilakukan pada tanggal 1 - 28 September 2018. Penelitian ini dilakukan dengan beberapa tahapan mulai dari tahap pendahuluan, pengumpulan dan pengolahan data, dan analisis dan kesimpulan.

\section{HASIL DAN PEMBAHASAN} Analisis Ukuran Produksi yang Optimal dengan Model Alternatif EPQ

Tabel 3.1 Ukuran Produksi Optimal EPQ Produk Ceba 125 Ec $50 \mathrm{ml}$

\begin{tabular}{|c|c|c|c|}
\hline Replikasi & $\begin{array}{c}\text { Q Optimal } \\
\text { (box) }\end{array}$ & $\begin{array}{c}\text { Frekuensi Q/ } \\
\text { 6bulan (kali) }\end{array}$ & T Produksi (hari) \\
\hline 1 & 165.907 & 7 & 24 \\
\hline 2 & 11.338 & 10 & 18 \\
\hline 3 & 11.250 & 11 & 17 \\
\hline 4 & 12.178 & 10 & 18 \\
\hline 5 & 16.904 & 8 & 22 \\
\hline
\end{tabular}

Tabel 3.2 Ukuran Produksi Optimal EPQ Produk Petrogud 200 Ec $500 \mathrm{ml}$

\begin{tabular}{|c|c|c|c|}
\hline Replikasi & $\begin{array}{c}\text { Q Optimal } \\
\text { (box) }\end{array}$ & $\begin{array}{c}\text { Frekuensi Q/ } \\
\text { 6bulan (kali) }\end{array}$ & T Produksi (hari) \\
\hline 1 & 2.922 & 10 & 17 \\
\hline 2 & 1.669 & 16 & 11 \\
\hline 3 & 3.009 & 10 & 18 \\
\hline 4 & 3.112 & 11 & 16 \\
\hline 5 & 2.770 & 10 & 18 \\
\hline
\end{tabular}

Tabel 3.3 UkuranProduksi Optimal EPQ ProdukTombak 189 Ec $400 \mathrm{ml}$

\begin{tabular}{|c|c|c|c|}
\hline Replikasi & $\begin{array}{c}\text { Q Optimal } \\
\text { (box) }\end{array}$ & $\begin{array}{c}\text { Frekuensi Q/ } \\
\text { 6bulan (kali) }\end{array}$ & T Produksi (hari) \\
\hline 1 & 1.619 & 8 & 22 \\
\hline 2 & 1.380 & 10 & 18 \\
\hline 3 & 1.777 & 7 & 26 \\
\hline 4 & 1.391 & 10 & 19 \\
\hline 5 & 1.872 & 8 & 23 \\
\hline
\end{tabular}

Tabel 3.4 UkuranProduksi Optimal EPQ ProdukKanon 400 Ec Btl Pet $400 \mathrm{ml}$

\begin{tabular}{|c|c|c|c|}
\hline Replikasi & $\begin{array}{c}\text { Q Optimal } \\
\text { (box) }\end{array}$ & $\begin{array}{c}\text { Frekuensi Q/ } \\
\text { 6bulan (kali) }\end{array}$ & T Produksi (hari) \\
\hline 1 & 603 & 12 & 16 \\
\hline 2 & 667 & 11 & 16 \\
\hline 3 & 840 & 8 & 22 \\
\hline 4 & 603 & 12 & 16 \\
\hline 5 & 840 & 8 & 23 \\
\hline
\end{tabular}

Tabel 3.5 Ukuran Produksi Optimal EPQ Produk Kanon 400 Ec Btl Pet $400 \mathrm{ml}$

\begin{tabular}{|c|c|c|c|}
\hline Replikassi & $\begin{array}{c}\text { Q Optimal } \\
\text { (box) }\end{array}$ & $\begin{array}{c}\text { Frekuensi Q/ } \\
\text { 6bulan (kali) }\end{array}$ & T Produksi (hari) \\
\hline 1 & 737 & 10 & 19 \\
\hline 2 & 611 & 11 & 16 \\
\hline 3 & 758 & 8 & 23 \\
\hline 4 & 651 & 11 & 16 \\
\hline 5 & 689 & 11 & 17 \\
\hline
\end{tabular}

Analisis Ukuran Produksi yang Optimal dengan model Alternatif Permintaan Musiman

Tabel 3.6 Ukuran Produksi Optimal Permintaan Musiman Produk Ceba 125 Ec 50ml

\begin{tabular}{|c|c|c|c|}
\hline Replikasi & $\begin{array}{c}\text { Q Optimal } \\
\text { (box) }\end{array}$ & $\begin{array}{c}\text { Frekuensi Q/ } \\
\text { 6bulan (kali) }\end{array}$ & T Produksi (hari) \\
\hline 1 & 2.941 & 42 & 4 \\
\hline 2 & 2.890 & 41 & 4 \\
\hline 3 & 2.839 & 43 & 4 \\
\hline 4 & 2.921 & 42 & 4 \\
\hline 5 & 3.510 & 40 & 5 \\
\hline
\end{tabular}

Tabel 3.7 Ukuran Produksi Optimal Permintaan Musiman Produk Petrogud 200 Ec 500ml

\begin{tabular}{|c|c|c|c|}
\hline Replikasi & $\begin{array}{c}\text { Q Optimal } \\
\text { (box) }\end{array}$ & $\begin{array}{c}\text { Frekuensi Q/ } \\
\text { 6bulan (kali) }\end{array}$ & T Produksi (hari) \\
\hline 1 & 743 & 41 & 4 \\
\hline 2 & 649 & 42 & 4 \\
\hline 3 & 744 & 41 & 4 \\
\hline 4 & 554 & 43 & 4 \\
\hline 5 & 644 & 43 & 4 \\
\hline
\end{tabular}

Tabel 3.8 Ukuran Produksi Optimal Permintaan

Musiman Produk Tombak 189 Ec 400ml

\begin{tabular}{|c|c|c|c|}
\hline Replikasi & $\begin{array}{c}\text { Q Optimal } \\
\text { (box) }\end{array}$ & $\begin{array}{c}\text { Frekuensi Q/ } \\
\text { 6bulan (kali) }\end{array}$ & T Produksi (hari) \\
\hline 1 & 317 & 42 & 4 \\
\hline 2 & 356 & 40 & 5 \\
\hline 3 & 311 & 41 & 4 \\
\hline 4 & 353 & 38 & 5 \\
\hline 5 & 359 & 41 & 4 \\
\hline
\end{tabular}

Tabel 3.9 Ukuran Produksi Optimal Permintaan Musiman Produk Kanon 400 Ec Btl Pet 400ml

\begin{tabular}{|c|c|c|c|}
\hline Replikasi & $\begin{array}{c}\text { Q Optimal } \\
\text { (box) }\end{array}$ & $\begin{array}{c}\text { Frekuensi Q/ } \\
\text { 6bulan (kali) }\end{array}$ & T Produksi (hari) \\
\hline 1 & 165 & 42 & 4 \\
\hline 2 & 179 & 42 & 4 \\
\hline 3 & 165 & 42 & 4 \\
\hline 4 & 166 & 42 & 4 \\
\hline 5 & 156 & 42 & 4 \\
\hline
\end{tabular}


Tabel 3.10 Ukuran Produksi Optimal Permintaan Musiman Produk Kanon 400 Ec Btl Pet $400 \mathrm{ml}$

\begin{tabular}{|c|c|c|c|}
\hline Replikasi & $\begin{array}{c}\text { Q Optimal } \\
\text { (box) }\end{array}$ & $\begin{array}{c}\text { Frekuensi Q/ } \\
\text { 6bulan (kali) }\end{array}$ & T Produksi (hari) \\
\hline 1 & 156 & 46 & 4 \\
\hline 2 & 144 & 48 & 4 \\
\hline 3 & 137 & 47 & 4 \\
\hline 4 & 163 & 45 & 4 \\
\hline 5 & 168 & 45 & 4 \\
\hline
\end{tabular}

Analisis Biaya Simpan dan Service Level dari masing-masing Model Alternatif Simulasi Produksi

Dari hasil simulasi produksi yang telah dilakukan, selanjutnya melakukan perhitungan service level dengan 2 model alternatif yang telah ditentukan. Didapatkan hasil sebagai berikut:

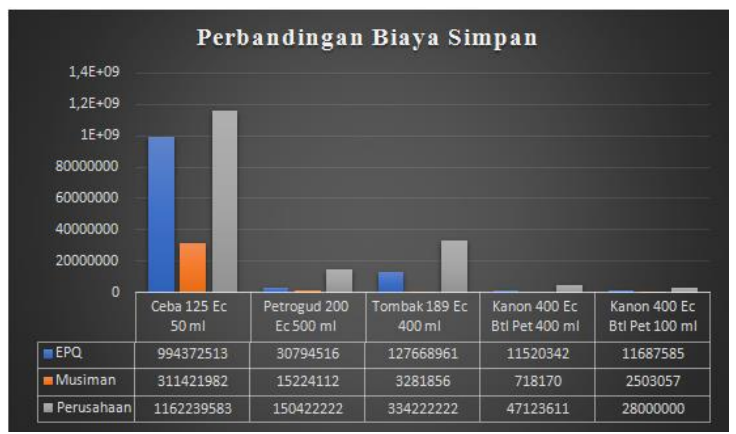

Gambar 3.1 Grafik Perbandingan BiayaSimpan EPQ, Permintaan Musiman dan Perusahaan

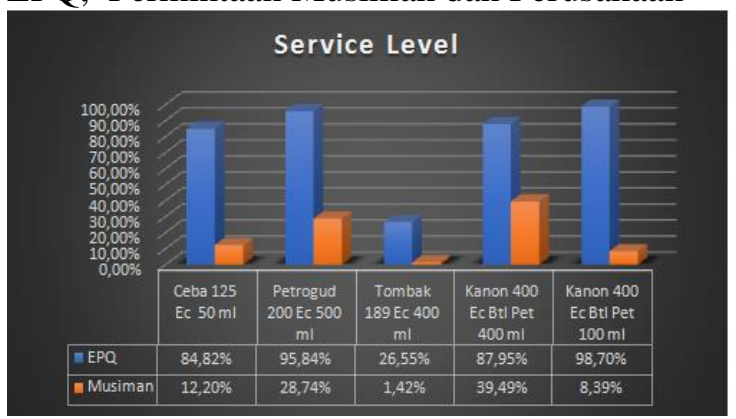

Gambar 3.2 Grafik Perbandingan Service Level EPQ dan Permintaan Musiman

Dari hasil grafik diatas menunjukkan bahwa kedua model alternatif memiliki biaya simpan lebih rendah dibandingkan dengan biaya simpan perusahaan. Jika dibandingkan hanya dari model alternatif, model permintaan musiman memiliki biaya simpan yang lebih rendah dibandingkan model EPQ. Namun, model EPQ memiliki service level melebihi model permintaan musiman, dimana hal ini menunjukkan bahwa model EPQ mampu memenuh permintaan pelanggan

\section{Analisis Hasil Simulasi Terbaik}

Dari hasil simulasi produksi yang telah dilakukan dan perhitungan biaya simpan dan service level dari masing-masing model alternatif, dapat dilihat bahwa model EPQ memberikan biaya simpan yang rendah dibandingkan perusahaa. Sehingga alternatif yang dipilih untuk jumlah produksi yang optimal adalah model EPQ.

Tabel 3.11 Hasil SimulasiTerbaikdengan Model EPQ

\begin{tabular}{|l|c|c|c|}
\hline \multicolumn{1}{|c|}{ Produk } & $\begin{array}{c}\text { Q Optimal } \\
\text { (box) }\end{array}$ & $\begin{array}{c}\text { Frekuensi Q/ } \\
\text { 6bulan (kali) }\end{array}$ & T Produksi (hari) \\
\hline Ceba 125 Ec - $50 \mathrm{ml}$ & 11.338 & 10 & 18 \\
\hline Petrogud 200 Ec $500 \mathrm{ml}$ (Pet) & 1.669 & 16 & 11 \\
\hline Tombak $189 \mathrm{Ec} 400 \mathrm{ml}$ & 1.380 & 10 & 18 \\
\hline Kanon 400 EcBtil Pet $400 \mathrm{ml}$ & 603 & 12 & 16 \\
\hline Kanon 400 EcBtl Pet $100 \mathrm{ml}$ & 611 & 11 & 16 \\
\hline
\end{tabular}

\section{KESIMPULAN}

Dari hasil pembahasan yang disertai dengan beberapa analisis, adapun hal-hal yang menjadi poin penting dan dapat ditarik menjadi kesimpulan yaitusebagai berikut:

1. Setelah melakukan perencanaan melalui simulasi dari data random dengan metode Monte Carlo didapatkan hasil dibawah ini:

a) Ukuran produksi dengan model EPQ didapatkan hasil sebagai berikut: Untuk produk Ceba 125 Ec $50 \mathrm{ml}$, Q optimal sebesar 11.338 box. Untuk produk Petrogud 200 Ec $500 \mathrm{ml}$, Q optimal sebesar 1.669 box. Untuk produk Tombak 189 Ec $400 \mathrm{ml}$, Q optimal sebesar 1.380 box. Untuk produk Kanon 400 Ec Btl Pet 400 ml, Q optimal sebesar 603 box. Untuk produk Kanon 400 Ec Btl Pet $100 \mathrm{ml}$, Q optimal sebesar 611 box.

b) Ukuran produksi yang optimal dengan model Permintaan Musiman didapatkan hasil sebagai berikut: Untuk produk Ceba 125 Ec $50 \mathrm{ml}$, Q optimal sebesar 3.510 box. Untuk produk Petrogud 200 Ec 500 ml, Q optimal sebesar 554 box. Untuk produk Tombak 189 Ec $400 \mathrm{ml}$, Q optimal sebesar 356 box. Untuk produk Kanon 400 Ec Btl Pet 400 ml, Q optimal sebesar 165 box. Untuk produk Kanon 400 Ec Btl Pet 100 ml, Q optimal sebesar 156 box.

Dalam penelitian ini terdapat 3 alternatif sistem persediaan yaitu EPQ, Permintaan Musiman dan Perusahaan. Dari 3 alternatif tersebut, dipilih model EPQ yang paling optimal karena diperoleh hasil sebagai berikut: Untuk produk Ceba 125 Ec 50 ml biaya simpan sebesar Rp. 994.372.513, service level 84,82\%. Untuk produk Petrogud 200 Ec $500 \mathrm{ml}$ biaya 
simpan Rp. 30.794.516, service level 95,84\%. Untuk produk Tombak 189 Ec $400 \mathrm{ml}$ biaya simpan Rp. 127.668.961, service level 26,55\%. Untuk produk Kanon $400 \mathrm{Ec}$ Btl Pet $400 \mathrm{ml}$ biaya simpan Rp. 11.520.342, service level $87,95 \%$. Untuk produk Kanon 400 Ec Btl Pet $100 \mathrm{ml}$ biaya simpan Rp. 11.687.585, service level $98,70 \%$.

\section{DAFTAR PUSTAKA}

Arifin, M. (2009). Simulasi Sistem Industri. Yogyakarta: Graha Ilmu.

Djati, B. S. (2007). Simulasi dan Teori Aplikasinya. Yogyakarta: C.V ANDI OFFSET.

Ginting, R. (2007). Sistem Produksi. Yogyakarta: Graha Ilmu.

Ginting, R. (2012). Sistem Produksi. Yogyakarta: Graha Ilmu.

Handoko, H. T. (1999). Dasar-dasar Manajemen Produksi dan Operasi. Surakarta: UNS PRESS.

Handoko, T. H. (2000). Dasar-dasar Manajemen Produksi. Yogyakarta: BPFE.

Heizer, J. H., \& Render, B. (2014). Operations Management: Sustainability and Supply Chain. Pearson.

Law, A. M., \& Kelton, W. D. (2000). Simulation Modeling and Analysis (3 ed.). (W. D. Kelton, Ed.) McGraw-Hill.

Mulyono, S. (2002). Riset Operasi. Jakarta: Fakultas Ekonomi Universitas Indonesia.
Nasution, A. H., \& Prasetyawan, Y. (2008). Perencanaan dan Pengendalia Produksi. Yogyakarta: Graha Ilmu.

Nasution, N. K. (2016, Desember). Prediksi Penjualan Barang Pada Koperasi PT. Perkebunan Silindak Dengan Menggunakan Metode Monte Carlo. Jurnal Riset Komputer, 3, 65-69.

Prasetiawan, A. (2014). Simulasi Penentuan Lot dalam Pengendalian Persediaan dengan Metode Simulasi Monte Carlo. Malang: Teknik Industri, Universitas Muhammadiyah Malang.

Prasetyowati, E. (2016, Februari). Aplikasi Simulasi Persediaan Teri Crispy Prisma Menggunakan Metode Monte Carlo. 1, 43-49.

Profita, A., Utomo, D. S., \& Fachriansyah, F. (2017). Optimsi Manajemen Persediaan Darah Menggunakan simulsi Monte Carlo. Samarinda: JIEM.

Pujawan, I. N., \& Mahendrawathi. (2010). Supply Chain Management (kedua ed.). (I. K. Gunarta, Ed.) Surabaya: Instut Teknologi Sepuluh Nopember.

Purnomo, H. (2004). Pengantar Teknik Industri. Yogyakarta: Graha Ilmu.

Ristono, A. (2009). Manajemen Persediaan. Yogyakarta: Graha Ilmu.

Roger, S. (2000). Pengambilan Keputusan Dalam Suatu Fungsi Operasi (Ketiga ed.). Jakarta: Erlangga. 
Santoso, B., Liliana, \& Yapitro, I. (2008). Tools Simulasi Inventori pada Supermarket. Seminar Nasional Informatika, 313314.

Sartika, R. (2014). Optimasi Persediaan pada Rantai Pasokan Beras untuk Program Raskin. Bogor: Sekolah Pascasarjana IPB.

Sofyan, D. K. (2013). Perencanaan dan Pengendalian Produksi. Yogyakarta: Graha Ilmu.

Veza, O. (2016, Oktober). Simulasi Pengendalian Persediaan Gas Menggunakan Metode Monte Carlo dan Pola LCM. JT-IBSI, 1, 1-15.

Warindra, A. S. (2017). Penentuan Ukuran Produksi Garmen untuk Memaksimalkan Keuntungan dengan Pendekatan Simulasi Monte Carlo. Universitas Muhammadiyah Gresik, Teknik Industri, Gresik. 